voción a quantos la mirasen y estando en oración con estas ansias se trasportó en un sueño misterioso; parecióle ver al Santo como de 20 años, vestido de las pieles con el pelo adentro y sentado en un peñasco y un cordero descansando la cabeza en su rodilla izquierda a quien el Santo por el mismo lado asía con su mano, y con la derecha le estaba señalando; parecióle cosa extraordinaria i más volviendo así (sic) después del sueño, le guardó tan fixa la representación que no pudo olvidarla y aunque dando parte de ella a las demás devotas la persuadían que hiciese la imagen en la forma común, ni vino en ello, ni jamás se pudo conformar, ni sosegar.

Resistióse, en fin, de executar el sueño, persuadida que era tan extraordinario no pudiera fabricar su fantasía, y así hizo llamar luego a Juan Bautista Montanés, excelentísimo escultor, y celebrado por famoso en la ciudad y en todo el Reyno y dándole quenta muy extensa de toda su intención, y sueño le encargó en toda su conformidad la echura de la imagen que al fin se hizo de la misma suerte, que la dicha $\mathrm{M}$. avía soñado, y admirado el mismo artífice le dixo ser aquella estatua y entalladura más propia de las oraciones de quien se le pidieron que de su idea y Arte y le parecía que no acertaría a hacer otra semejante en los primores que en ella conocía, como le sucedió después queriéndole imitar al hacer otras sin atinar con igualdad a la primera hecha, pues la imagen, el retablo y ornamento se formó el altar y se adornó del todo, lo que la dicha $\mathrm{M}$. y las devotas quedaron satisfechas y han concertado todas hasta ora que varios esculptores traídos de la fama han visto y le han dado aquella imagen y queriéndola imitar han confesado que hechuras desdicen siempre mucho de ese original» 6 .

\title{
Balbino Velasco
}

\section{UNA NUEVA OBRA DE JUAN DE JUANES EN ATIENZA*}

En el nuevo Museo de la iglesia de San Gil de Atienza -Guadalajara-, se halla una tabla denominada Nuestra Señora de Belén en la cartela del Museo. Esta obra procede según Francisco Layna Serrano, del Hospital de San Salvador, de dicha villa (Figs. 8 y 9) ${ }^{1}$. Su tema puede considerarse también como el retrato de la Virgen. Se trata de un tipo que usa como modelo iconográfico un primitivo icono de procedencia oriental, que emula el supuesto retrato que hizo San Lucas de María 2.

La referencia más antigua que he encontrado de esta obra, es una reproducción fotográfíca anterior a la Guerra Civil, que se halla en el Archivo Fotográfico T. Camarillo, en la Biblioteca de la Diputación Provincial de Guadalajara. Lo más sorprendente es el rótulo a pie de página que allí figura, pues se juzga "presunto retrato de Isabel la Católica». Sin duda el pequeño formato de la obra, el hecho de representar el busto de una figura femenina y el remoto parecido con los nume-

${ }_{6}$ Roma, Arch. Postulación General, O. Carm., IV, 46, Vitae servorum Dei, f. 220 r ss. Se encuentra este archivo en la Vía Sforza Pallavicini 10. No hay duda que el manuscrito es obra del P. Quesada, como demuestra el P. Ismael Martínez Carretero, O. Carm. (Venerables Sevillanos, pro ms.). La coincidencia de la estatua con la descripción del P. Quesada está fuera de duda, lo que naturalmente disipa la incógnita que apunta el profesor Hernández Díaz.

* En primer lugar quiero agradecer a D. José Rogelio Buendía su ayuda en la elaboración de este artículo y sus enseñanzas como Director de mi Tesis Doctoral, así como a D. Agustín, párroco de Atienza, por las facilidades dadas en la investigación acerca de esta obra.

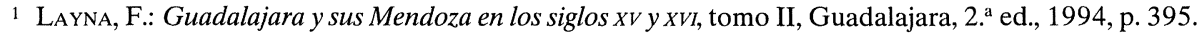

2 ALBI, J.: Joan de Joanes y su círculo artístico, tomo II, Valencia, 1979, p. 232. 
rosos retratos de la Reina Católica que existen ${ }^{3}$, hicieron pensar que esta obra pudiese representarla, dado que no hay apenas rasgos individualizadores. Pero más extraño resulta comprobar que Layna Serrano está de acuerdo con dicha afirmación, pues considera que se trata de una buena copia del retrato que Antonio del Rincón hizo de Isabel la Católica ${ }^{4}$. El interés de Layna por dotar a la personalidad de Rincón de una mayor presencia en la crítica, le debió llevar a esta conclusión, en un momento en el que este «mito» estaba sufriendo una investigación historiográfica profunda y en todo punto infructuosa, a cargo de Elías Tormo y de F. Javier Sánchez Cantón ${ }^{5}$. Layna Serrano denomina a Tormo "docto e impetuoso académico", y se lamenta que a partir de su artículo sobre el retablo de Robledo de Chavela ${ }^{6}$, predominen los que duden de la existencia de un pintor cuyo nombre figura ya en una calle de Guadalajara. Acaba mencionando unos documentos que probarían la existencia del pintor, que no pudieron publicar por haber muerto, ni Sentenach ni Serrano Sanz -tío de Layna Serrano-, pero confía que alguien los encuentre, con lo que Tormo y Sánchez Cantón tendrían que retractarse de sus «dogmáticas afirmaciones" ${ }^{7}$. Como vemos, Layna se deja llevar por el fervor hacia su patria chica y pese a darse cuenta que esta Virgen de Belén es una obra posterior al reinado de Isabel, se obsesiona con que ha de ser una de las mejores copias del retrato que de dicha reina debió haber ejecutado su pintor de Cámara Antonio del Rincón 8 .

En realidad esta tabla es idéntica al Rostro de la Virgen, proveniente de un relicario de la parroquia de San Nicolás de Valencia, la cual estaba unida por el reverso a un Salvador-Cabeza de Cristo-,. de la que fue separada en 1882. Para José Albí ${ }^{9}$, las dos caras de la tabla son de Juan de Juanes. El modelo usado como dije anteriormente, es oriental, retomado a través de algunos precedentes valencianos entre los que podemos mencionar el conocido como la Verónica del Rey Martín ${ }^{10}$. Juan de Juanes humaniza y da una versión típicamente suya de este tema en la pintura de San Nicolás. Albí no comenta esta representación porque sigue los mismos principios que el Salvador al que estaba unida. Incomprensiblemente data este Salvador hacia 1560, cuando se halla material y estilísticamente unido al Rostro de la Virgen, cuya inscripción fecharía ambas obras en 1572.

Se puede extender al Rostro de la Virgen los adjetivos de serena, mansa, inexpresiva, equilibrada o armónica, que Albí adjudica a la Cabeza de Cristo de su reverso. En cuanto a la técnica ocurre lo mismo, en ambas obras, Juanes trabaja como un miniaturista, acariciando la tabla con una minuciosidad ${ }^{11}$ que no se encuentra en sus pinturas de mayor tamaño. No veo la razón de separar en diez años dichas obras, pese a que Albí encuentre relación con los retablos del Gremio de Pelaires, realizados para esa misma parroquia de San Nicolás, en la que hay numerosas obras de Juanes. Si comparamos esta Cabeza de Cristo con la que aparece en la Santa Cena de la citada parroquia, vemos en esta última una menor serenidad e idealización ${ }^{12}$. Es mucho más sencilla la relación de las dos tablas que formaban el relicario - unidas por el reverso y desmon-

\footnotetext{
3 Museo del Prado, Palacio Real de Madrid, Palacio de Windsor.

4 Layna, F. (1994), p. 395.

5 Sánchez Cantón, F. J.: «Mito y realidad de Rincón, pintor de los Reyes Católicos», Las Ciencias, 1934, pp. 136-144.

6 Tormo, E.: «El retablo de Robledo de Chavela. Antonio del Rincón, pintor de los Reyes Católicos», B.S.E.E., 1904, pp. 477-486.

7 LAYNA, F. (1994), pp. 395-396.

8 Palomino, A.: Museo pictórico y escala óptica. Tomo II, Madrid, 1724, p. 234.

9 Albi, J. (1979): pp. 231-232.

10 Otro ejemplo se halla en el Museo de Valencia, es una tabla pintada también por ambos lados, Pedro Nicoláu pinta en uno de ellos el Rostro de la Virgen, orlado por doce estrellas simbólicas, dentro del estilo internacional. En GariN Ortiz, F. M.: El Museo de Valencia, Madrid, 1964. p. 14.

11 Albf, J. (1979): tomo II, pp. 130-131.

12 Albf, J. (1979): tomo III. En este tercer tomo de la obra dedicada a Juan de Juanes, hay fotografías de casi todas las obras a las que hago referencia.
} 

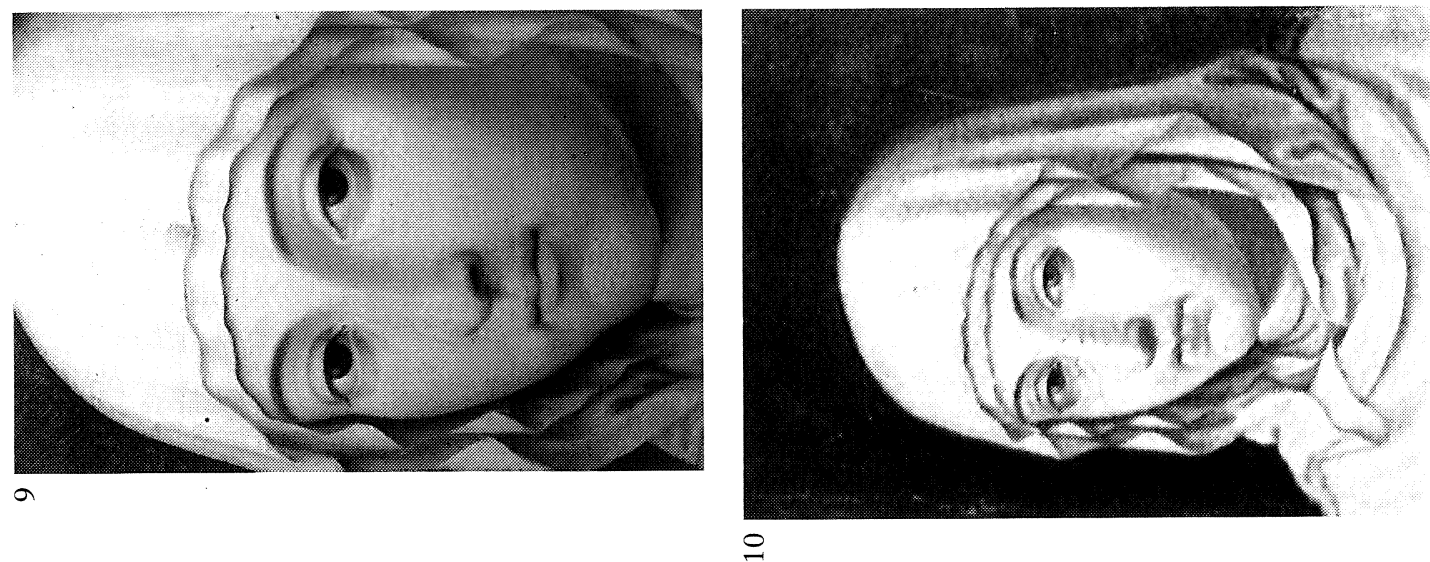

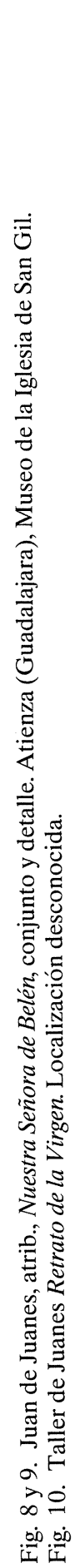

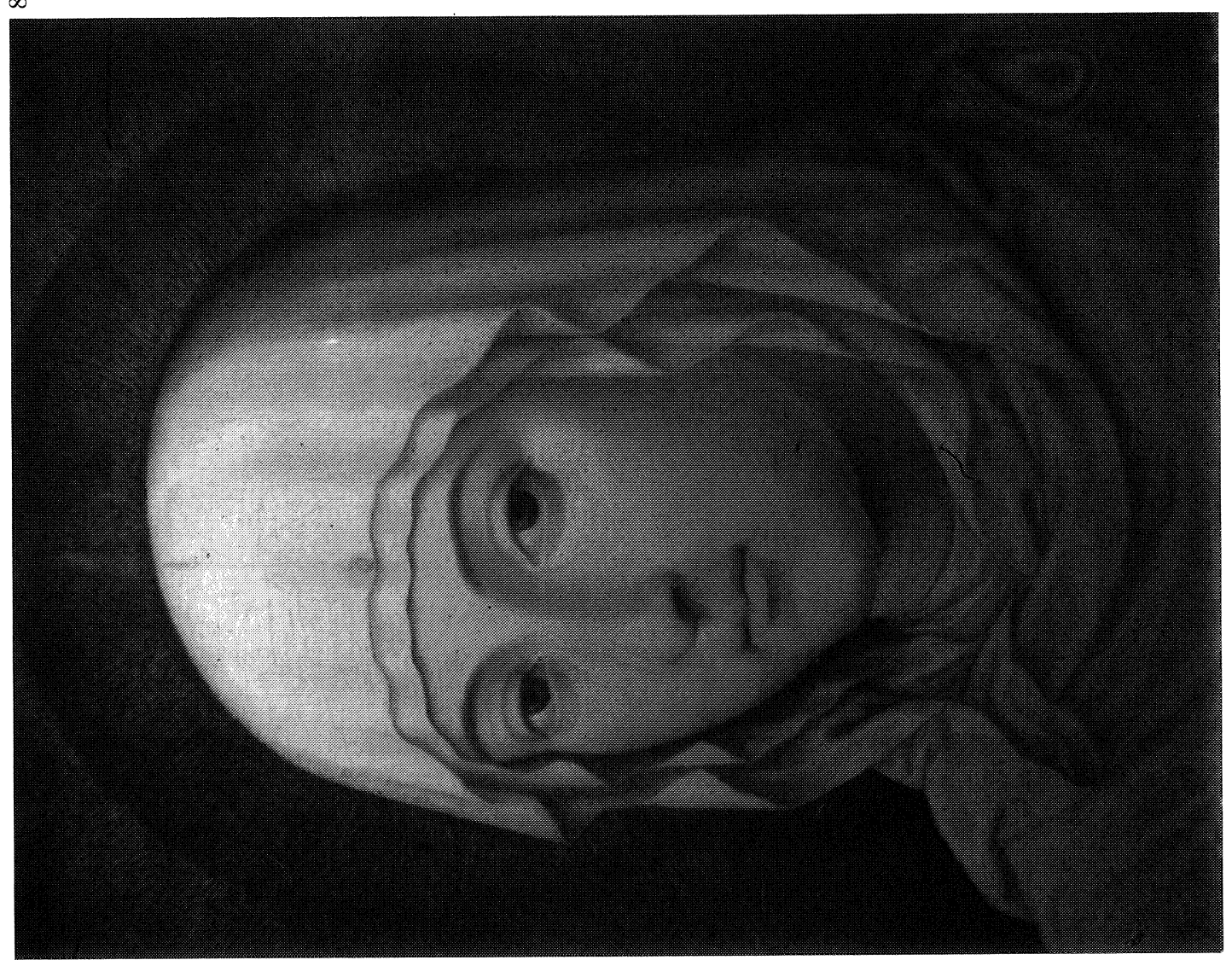


tadas por el párroco D. Salvador Gay en 1882. La serenidad armónica y la inexpresividad de este rostro, sólo se alcanza en la parte final de la carrera de Juan de Juanes -Asunción de la Virgen del Museo de Valencia, Inmaculada de la Iglesia de la Compañía en Valencia, Sagrada Familia de la Academia de San Fernando...-. En este momento es en el que la identificación entre belleza formal y bondad espiritual alcanza su mayor y más clara expresión, en un periodo en el que vacila entre las novedades artísticas surgidas tras el Concilio de Trento y su temperamento estático, delicado y sentimental ${ }^{13}$. Ante su falta de capacidad de asimilación durante los años setenta, triunfa el tradicionalismo repetitivo, salvo algunas obras como la Crucifixión de la Colección Lasala de Valencia.

Volvamos a Nuestra Señora de Belén del Museo de San Gil de Atienza. Las características fundamentales que definen este rostro son un idealismo sentimental, una serena inexpresividad y un gran sentido de la delicadeza. Hay una búsqueda no esteticista sino moral de la belleza -identificación platónica y agustiniana entre bondad y belleza-. Todas estas características son propias de la obra de Juan de Juanes en las distintas etapas de su carrera, sin embargo los rasgos faciales de la Virgen de Atienza, siguen un modelo tardío en la trayectoria del pintor valenciano, que no sólo aparecen en las pinturas del relicario de San Nicolás, sino en otras como las Inmaculadas de Sot de Ferrer y de la Iglesia de la Compañía de Valencia, de la Virgen de la Esperanza de la Colección Barón Casa Soler de Valencia o de los mismos rostros de sus Salvadores-iglesia de Sot de Chera, Colección Perdigó, Museo de Valencia, etc.-. Este tipo facial posee boca pequeña y totalmente cerrada -a diferencia de obras un poco más expresivas y teatrales como el Retablo de San Esteban del Museo del Prado, que pintara en la década de los sesenta ${ }^{14}$,, labios finos y sinuosos con la comisura delicadamente marcada, nariz recta y unida a la frente sin curvarse y ojos ovalados bajo cejas finas que siguen un trazado eminentemente geométrico. El rostro se enmarca en un óvalo con la mejillas carnosas que recuerdan las formas rellenas de Durero ${ }^{15}$. Todo en esta cara es igual al Rostro de la Virgen de San Nicolás, y no sólo en la cara sino también en los pliegues delicados y armónicos que le caen por los hombros, dentro de la tradición juanesca. Por lo demás, el fondo monócromo y el modo de señalar el nimbo a base de finas líneas radiales nos remiten a esta obra valenciana, atribuida por Albí con seguridad a Juan de Juanes. En cuanto a la versión atencina. Albí la califica con dudas, de obra de taller, aunque con reservas derivadas de la no observación directa de la obra ${ }^{16}$.

Según mi parecer, el estudio estilístico de la obra se suma al análisis moreliano de las formas para poder atribuir el Rostro de la Virgen del Museo de San Gil de Atienza a Juan de Juanes, quizá sin intervención de taller, pues no se advierten variantes técnicas ni estilísticas. Si bien es cierto que la pincelada de esta versión guadalajareña es más compacta -más cuatrocentista podríamos decir- que en la mayoría de las obras de Juan de Juanes, esto lo podemos explicar por el tamaño reducido de la pintura ${ }^{17}$, que la desmarca de las grandes composiciones retablísticas en las que la esfumatura leonardesca se deja ver sobre todo en los paisajes de fondo, ensoñadores y clásicos casi al modo de Aníbal Carracci. La pincelada en el Rostro de la Virgen de Atienza es muy suave, de un escaso espesor -como se puede ver en un pequeño desconchón, que nos deja ver la preparación en tonos claros de la tabla-, fina y sinuosa, sin requiebros agrios y disonantes. El colorido es limpio y brillante, como lo definió Diego Angulo ${ }^{18}$, para conseguir esa suavidad

13 Albi, J. (1979): tomo II, pp. 368-377.

14 AlBi, J. (1979): tomo II, pp. 142-145 y 357-358.

15 Angulo, D.: Ars Hispania. Pintura del Renacimiento, tomo XII, Madrid, 1954, p. 165. Ponía en relación la Virgen del Mono de Durero, con la Sagrada Familia de la Academia de San Fernando de Madrid.

16 Albf, J. (1979): tomo II, p. 232.

17 Las medidas del cuadro son 25,8 cm de anchura y 34,9 de altura.

18 Angulo, D. (1954): p. 164. 
cristalina en las sombras de la que habló Camón Aznar en relación a la Inmaculada de la iglesia de la Compañía ${ }^{19}$, datable también en los últimos años del autor. No obstante, debemos tener en cuenta que la calidad técnica de alguno de sus seguidores, sobre todo Nicolás Borrás, no nos permite afirmar con rotundidad la autoría de Juanes, si bien nos inclinamos por ella.

Todo ello nos hace pensar, que esta obra fue pintada por Juan de Juanes en la última época de su vida, quizá entre 1570 y 1575.

En los fondos Fotográficos del Servicio Nacional de Recuperación Artísticoa que se guardan en el Departamento "Diego Velázquez" del C.S.I.C., existe la fotografía de un cuadro que representa también el Rostro de la Virgen. Es una tabla distinta a las versiones de Valencia y de Atienza, ya que no tiene nimbo como éstas. Por lo que se puede apreciar a través de la fotografía, parece una obra de taller, a causa de la mayor dureza de los rasgos y de la menor delicadeza de las sombras, o bien una copia de un artista poco dotado; lo que no sería de extrañar dado el éxito popular de las obras de Juan de Juanes. El rostro es más alargado, los ojos están un poco más cerrados y la barbilla se marca en exceso. No obstante es una copia fiel de la obra de Juanes e imita con escrupulosidad casi todos los pliegues del ropaje por lo que quizá tuvo delante el original del maestro (Fig. 10).

F. Javier RAMOs GÓMEZ Becario Universidad Autónoma

\section{NOTICIAS DOCUMENTALES SOBRE MORO ¿O KEY? Y SOBRE EL CARAVAGGIO}

Los especialistas de la pintura flamenca del siglo xvi conocen bien los magníficos retratos de Antonio del Río, Señor de Cleydael y de Aertselaer, y el de su esposa Leonor López de Villanueva, conservados en el museo del Louvre. Se presumía su procedencia española pues procedían de la colección del General Conde de Armagnac, reunida en su mayoría en España. Se ha destacado la personalidad del retratado, acompañado de sus hijos, uno de los cuales, Martín Antonio, fue famoso teólogo jesuita, y la de su esposa pero se ha discutido su clasificación. Algunos autores, como Friedländer e Hymans, los atribuyeron a Antonio Moro pero posteriormente el Catálogo del Museo del Louvre los consideró obra de Willem Key (Figs. 11 y 12) ${ }^{1}$.

Se ha localizado ahora la procedencia exacta de estos retratos y su pertenencia a un tríptico de mayores dimensiones. Aunque la noticia no desvela el nombre de su autor, quizás apunta más hacia Moro.

En los documentos que el Archivo Histórico Nacional conserva del Convento de la Trinidad de Burgos, se localizaron referencias sobre la Capilla de la Resurrección, dotada por Jerónimo del Río, casado con Clara Manrique de Lara, de la familia protectora de este convento. Entre los papeles se incluye el testamento de Antonio del Río, natural de Lisboa y que había redactado el documento en esta ciudad el año de 1584, fecha que no coincide con la de 1582 que aparece en otra referencia ${ }^{2}$.

19 Camón Aznar, J.: Summa Artis. Pintura del siglo xvi, tomo XIV, Madrid, 1978, pp. 92-100.

1 Hymans, H.: Antonio Moro. Son oeuvre et son temps, Bruxelles, 1910, págs. 146-148, láms. 43-44. Miden 1,66 x 0.80 m. Friedländer, M.: Die altniederländische Malerei Antohonis Mor and seine Zeitgenossen, Leiden, 1936, vol. Xlll. La Peinture du Musée du Louvre. T. II. Les écoles étrangères. Publié sous la direction de Jean Guiffrey, Paris, 1941, láms. 43-44, pág. 44 (bajo el nombre de Key). Jordan, A. M.: Retrato de Corte en PortugaL O Legado de Antonio Moro (1552-1572), Lisboa, Querzal, edit. 1994.

2 Archivo Histórico Nacional (AHN). Sección de Clero, Burgos, Trinitarios. Legajo 1017. 